\title{
Hepatocyte proliferation rate is a powerful parameter for predicting hepatocellular carcinoma development in liver cirrhosis
}

M Borzio, D Trerè, F Borzio, A R Ferrari, S Bruno, M Roncalli, G Colloredo, G Leandro, F Oliveri, M Derenzini

\section{Abs
for
at
car
the
sion
reg
for
cin
Met}

Aims-A sound predictive test is lacking for the identification of cirrhotic patients at high risk of developing hepatocellular carcinoma. The present study evaluates the measurement of hepatocyte expression of silver stained nucleolar organiser region (AgNOR) proteins as a risk factor for the development of hepatocellular carpatients included in a follow up surveillance programme for hepatocellular carcinoma development were evaluated prospectively for hepatocyte AgNOR protein quantity. The follow up programme consisted of clinical and biochemical assessment every three months, and ultrasound scanning and serum $\alpha$-fetoprotein $(\alpha F P)$ assessment every six months. Histological sections from the needle biopsies performed at enrollment were stained selectively for AgNOR proteins and the percentage of hepatocytes with an AgNOR protein area $\geqslant 7 \mathrm{~mm}^{2}$, indicative of a proliferative state (AgNOR proliferation index (AgNOR-PI)), was measured.

Results-During the mean (SD) follow up time of 65.5 (36.29) months (range, 12-143; median, 67), hepatocellular carcinoma was diagnosed in 48 of 176 patients (27.3\%). The AgNOR-PI of the whole series ranged from $0 \%$ to $5 \%$ (median, $0.9 \%$ ), and was significantly higher in patients with liver cell dysplasia and hepatitis B surface antigen (HBsAg) positivity $(\mathrm{p}<0.0001$ and $\mathrm{p}=0.0002$, respectively). The 176 patients were divided into two groups according to their AgNOR-PI scores; a cut off value of $2.5 \%$ defined by the receiver operating characteristic curve and the Youden index was used. Forty two patients were included in the high AgNOR-PI (<2.5\%) group, and 134 patients the low AgNOR-PI (<2.5\%) group. In the high AgNOR-PI group, 25 of 42 patients developed hepatocellular carcinoma, in contrast to only 23 of 134 patients $(17.2 \%)$ in the group with a low AgNOR-PI $(p<0.0001)$. Hepatocellular carcinoma development was also significantly more frequent in patients with liver cell dysplasia and HBsAg positivity. Multivariate analysis using AgNOR-PI, liver cell dysplasia, HBsAg positivity, and hepatitis $\mathrm{C}$ virus (HCV) infection as covariates demonstrated that the AgNOR-PI parameter was the only significant predictor of hepatocellular carcinoma development.

Conclusions-These results demonstrate that a high hepatocyte proliferation rate is a major risk factor for hepatocellular carcinoma development in the cirrhotic liver. Therefore, the evaluation of the hepatocyte proliferation rate is very important to identify patients requiring a more strict follow up programme for early diagnosis of hepatocellular carcinoma. (F Clin Pathol: Mol Pathol 1998;51:96-101)

Keywords: liver cirrhosis; hepatocellular carcinoma; hepatocyte proliferation; AgNOR proteins; image analysis; multivariate analysis

Hepatocellular carcinoma is one of the most common causes of death from neoplasia in the world, with an annual incidence of 259000 . Hepatocellular carcinoma is associated with chronic liver disease, mainly cirrhosis. The clinical outcome of patients with hepatocellular carcinoma is very poor, although early diagnosis can increase the benefit from appropriate surgical or medical treatment. ${ }^{1}$ Identification of chronic liver disease patients at high risk of developing hepatocellular carcinoma must therefore be the goal of any screening programme. In cirrhotic patients, evidence from prospective studies indicates that hepatitis B virus (HBV) and hepatitis $\mathrm{C}$ virus (HCV) infection, age over 60 years, and liver cell dysplasia are the major risk factors for hepatocellular carcinoma. ${ }^{23}$ In a preliminary study carried out in 33 patients with chronic liver disease, Derenzini et al demonstrated that a high silver stained nucleolar organiser region (AgNOR) protein quantity was associated with increased risk of hepatocellular carcinoma development. ${ }^{4}$

The AgNOR proteins are a set of nucleolar proteins that are necessary for ribosomal biogenesis. ${ }^{5}$ Their quantity increases progressively when resting cells enter the mitotic cycle from $G_{1}$ to $S$ phase ${ }^{6}{ }^{7}$ In regenerating rat hepatocytes, at the end of the $S$ phase, the mean AgNOR protein quantity measured in histological sections by morphometric analysis was about two times greater than that of resting hepatocytes $\left(7.18 \mu \mathrm{m}^{2}\right.$ versus $3.14 \mu \mathrm{m}^{2}$, respectively). ${ }^{6}$ In normal human hepatocytes, the AgNOR protein quantity was the same $\left(3.20 \mu \mathrm{m}^{2}\right)$ as in normal rat hepatocytes. ${ }^{8}$ 
Therefore, AgNOR protein amounts $>7 \mu \mathrm{m}^{2}$ can be considered to be indicative of the proliferative state in human hepatocytes.

The present study aimed to extend our preliminary observations regarding the relation between AgNOR protein quantity and the risk of hepatocellular carcinoma development in chronic liver disease patients. This was to establish definitively whether a high AgNOR protein quantity of hepatocytes in cirrhotic livers is an important risk factor for the onset of hepatocellular carcinoma. For this purpose, the percentage of hepatocytes with an AgNOR protein amount $\geqslant 7 \mu \mathrm{m}^{2}$ (AgNOR proliferation index (AgNOR-PI)) was evaluated by image analysis on histological sections of routinely processed liver biopsies in a series of 176 cirrhotic patients. The patients were included in a programme for hepatocellular carcinoma development surveillance and were followed for a median of 67 months (range, 12-143). Our results demonstrated that in the group of patients with high AgNOR-PIs the onset of hepatocellular carcinoma was significantly greater than in the group of patients with low AgNOR-PIs. Moreover, multivariate analysis performed to include the other well established prognostic variables (liver cell dysplasia, hepatitis B surface antigen (HBsAg) positivity, and $\mathrm{HCV}$ infection) showed that the AgNOR parameter was the only independent predictor of hepatocellular carcinoma development.

\section{Methods and materials}

PATIENTS

This study was carried out on 176 consecutive patients (98 men and 78 women; mean (SD) age, 56 (11) years) with well compensated liver cirrhosis, admitted to the department of medicine of Fatebenefratelli Hospital (Milan, Italy) for liver biopsy between January 1984 and November 1990. The following exclusion criteria were applied: (1) age over 70 years; (2) impossible to perform liver biopsy because of clotting abnormalities or presence of ascites; (3) inadequate liver sample for histological evaluation (section area less than 50 microscopic fields at $\times 40$ magnification); (4) evidence of hepatic malignancy detected by ultrasound scan or $\alpha$ fetoprotein $(\alpha \mathrm{FP})>400 \mathrm{ng} /$ $\mathrm{ml}$; (5) evidence of extrahepatic neoplasms; (6) Child's class C cirrhosis; (7) impossible to undergo regular follow up.

On recruitment, serological and biochemical screening including standard liver function tests; measurement of $\alpha \mathrm{FP}$, iron, ferritin, hepatitis $\mathrm{B}$, and hepatitis delta virus serum markers; and measurement of antismooth muscle, antinuclear, and antimitochondrial serum antibodies were carried out for each patient. Cirrhosis was classified using the Child-Turcotte score modified by Pugh. The serological test for antiHCV antibodies, in use from only 1990, was performed on 80 available stored baseline sera. Serum markers for $\mathrm{HBV}$ and $\alpha \mathrm{FP}$ were tested by commercial radioimmunoassay kits. Serum anti-HCV antibodies were assayed by the Ortho-HCV enzyme linked immunosorbent assay first generation test (Ortho Diagnostics,
Raritan, New Jersey, USA). ${ }^{9}$ The follow up programme included clinical and biochemical assessment every three months and ultrasound scanning and serum $\alpha \mathrm{FP}$ measurements every six months. Every focal liver lesion detected by ultrasound scanning appearing during follow up was investigated by fine needle biopsy and histologically examined to ascertain its benign or malignant nature. Diagnosis of hepatocellular carcinoma was further confirmed by computerised tomography after arteriography plus Lipiodol injection.

\section{HISTOLOGY}

Liver biopsies were fixed in $10 \%$ buffered formalin and paraffin wax embedded. Tissue sections were routinely stained with haematoxylin and eosin, PAS and PAS diastase for glycogen, Perls's stain for iron, and trichrome for collagen. Sections were also impregnated with silver for measurement of reticulin framework. One additional section was stained with silver colloid for AgNOR analysis. ${ }^{10}{ }^{11}$ The diagnosis of cirrhosis and hepatocellular carcinoma was based on internationally accepted histological criteria. ${ }^{12}{ }^{13}$ Diagnosis of large liver cell dysplasia was made according to Anthony and colleagues. ${ }^{14}$

AgNOR STAINING, QUANTITATIVE ANALYSIS OF AgNOR PROTEINS, AND AgNOR-PI ESTIMATION Histological sections were stained with silver for AgNOR proteins. ${ }^{10}{ }^{11}$ Sections were mounted on poly-L-lysine pretreated slides, dewaxed in xylene and ethanol, and progressively rehydrated. Slides were then removed from water to heat resistant plastic slide holders, fully immersed in $10 \mathrm{mM}$ sodium citrate buffer ( $\mathrm{pH}$ 6.0), and boiled in a commercially available pressure cooker at $120^{\circ} \mathrm{C}$ for 20 minutes. ${ }^{11}$ After cooling to room temperature, sections were stained with silver according to the "one step" method originally described by Ploton and co-workers. ${ }^{10}$ Silver staining was carried out using a solution of one volume $2 \%$ gelatin in $1 \%$ aqueous formic acid and two volumes of $50 \%$ silver nitrate. The staining reaction was performed for 10 minutes at $37^{\circ} \mathrm{C}$. After washing, the sections were dehydrated and mounted in a synthetic medium. Quantitative analysis of AgNOR proteins was performed by measuring the area of silver stained structures within the nuclei of hepatocytes present in the whole section of the biopsy specimen at high magnification $(\times 40)$, using a specific program of a computer assisted image analysis system (VIDAS, Kontron Elektronik, Eching, Germany). Liver sections with an area less than 50 microscopic fields were not considered suitable for the study. The average numbers of hepatocytes included in 50 fields were $\sim 2000$. Hepatocytes with more than one nucleus were not considered for AgNOR protein area evaluation. The AgNOR-PI, expressed as the percentages of hepatocytes with AgNOR protein area $\geqslant 7 \mu \mathrm{m}^{2}$, was automatically obtained at the end of each case. A similar procedure has been used previously to determine the AgNOR protein quantitative expression in human cancer lesions. ${ }^{1516}$ 


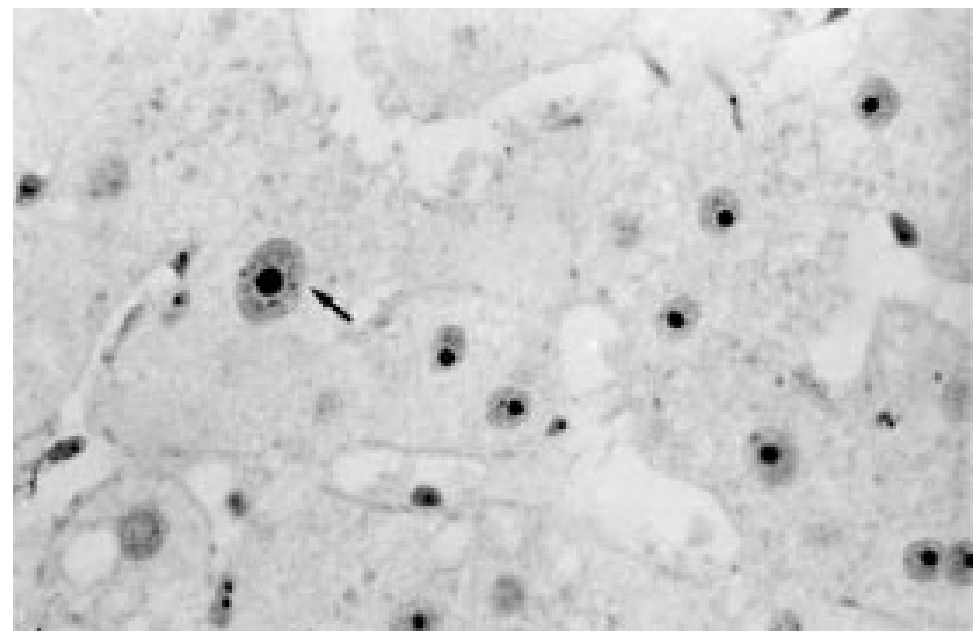

Figure 1 Cirrhotic liver section stained selectively for AgNOR proteins. A hypertrophic hepatocyte nucleus is visible (arrow) with a large amount of AgNOR proteins (original magnification, $\times 750$ ).

STATISTICAL ANALYSIS

Differences in the mean AgNOR protein area values between groups of patients divided according to baseline clinical, biochemical, and histological parameters were evaluated by the analysis of variance. The best cut off level for AgNOR-PIs was obtained by the receiver operating characteristic curve and the Youden index calculated by a specific computer program. The Youden index $(\mathrm{J}=$ sensitivity + specificity -1$)$ was preferred to the index of validity because of its major advantage of avoiding prevalence. Hepatocellular carcinoma free survival time was considered as the interval elapsing from the date of admission to the date of hepatocellular carcinoma diagnosis, death, drop out, or the end of November 1995, and it was calculated using the Kaplan-Meier method. ${ }^{17}$ Differences between curves were evaluated by both the Mantel Cox and the Breslow tests. To estimate the risk factors associated with hepatocellular carcinoma development, Cox's proportional hazard regression analysis was carried out. ${ }^{18}$ Proportionality assumption was verified by plotting $\log (-\log ($ survivor function) $)$ against time in different groups identified by each covariate to check parallelism. The maximum par-

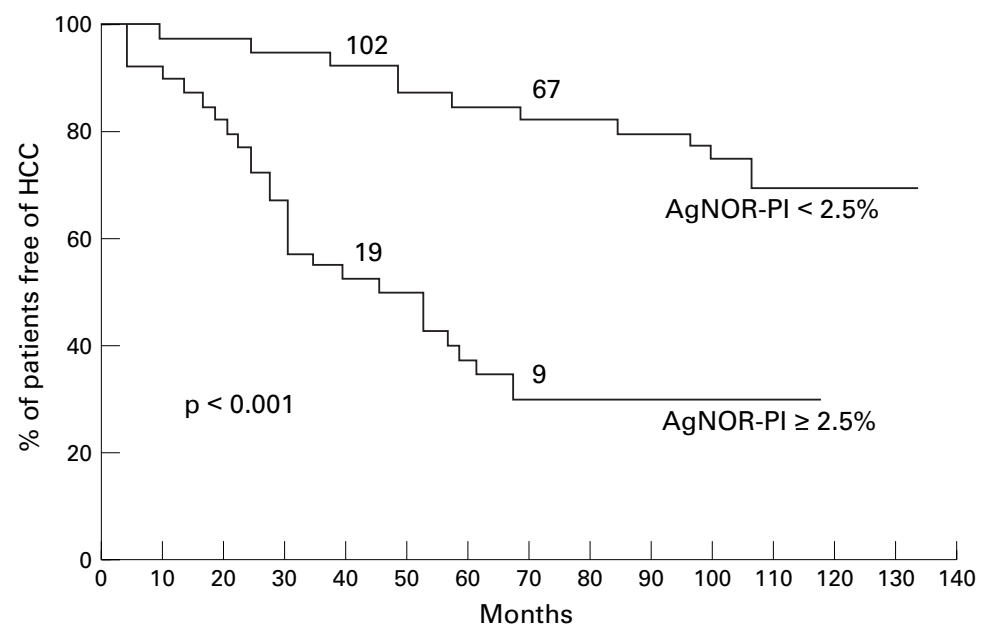

Figure 2 Cumulative probability of remaining hepatocellular carcinoma (HCC) free (Kaplan-Meier method) in cirrhotic patients according to AgNOR-PI. tial likelihood ratio test was used to assess the significance probability of each variable to be entered or removed, with all variables in the regression model at the start of analysis. All others were default parameters of the BMPD statistical package. Data were expressed as means (SD) and as odds ratios and 95\% confidence intervals (CI). Differences with $\mathrm{p}$ values $<0.05$ were considered significant.

\section{Results}

At the time of recruitment, the aetiology of cirrhosis was considered to be alcohol related in $62(35.2 \%)$ patients with a history of chronic daily alcohol intake of $>80 \mathrm{~g}$; HBV related in 31 (17.6\%) HBsAg serum positive patients; secondary to genetic haemochromatosis in three $(1.7 \%)$ patients; and cryptogenic in 80 $(45.5 \%)$ patients, in whom no aetiological factor could be identified. An anti-HCV test was performed on the 80 available frozen serum samples, and 42 were positive. Of the $42 \mathrm{HCV}$ positive cirrhosis cases, 11 had been classified as alcohol related and 31 as cryptogenic.

On admission, 42 patients had liver cell dysplasia $(23.9 \%)$. Only two of the $42 \mathrm{HCV}$ positive cirrhosis cases showed liver cell dysplasia.

Figure 1 shows a histological section from a cirrhotic liver after selective staining for AgNOR proteins. A hypertrophic hepatocyte nucleus is visible with a greater amount of AgNOR proteins (AgNOR protein area $=9.90 \mu \mathrm{m}^{2}$ ) than the surrounding resting hepatocyte nuclei (mean AgNOR protein area $=2.98 \mu \mathrm{m}^{2}$ ). Hepatocytes with a high AgNOR protein quantity were found in focal clusters as well as randomly distributed within the cirrhotic nodules. Hepatocytes with an AgNOR protein area $\geqslant 7 \mu \mathrm{m}^{2}$ were frequently located in dysplastic zones. However, they were also found in samples where liver cell dysplasia was absent.

In the 176 patients evaluated, the AgNOR-PI ranged from $0 \%$ to $5 \%$, with a median value of $0.9 \%$. AgNOR-PI values were found to be significantly greater in patients with liver cell dysplasia than those without $(2.49 \% \quad(1.5 \%)$ versus $1.02 \% \quad(1.07 \%)$; $\mathrm{p}<0.0001$ ), and in HBsAg positive patients than in those HBsAg negative $(2.16 \%(1.65 \%)$ versus $1.19 \%(1.20 \%) ; \mathrm{p}=0.0002)$. In contrast, no correlation was found between AgNOR-PI and HCV infection. In fact, the mean AgNOR-PI of HCV positive patients was not significantly different from that of $\mathrm{HCV}$ negative patients $(0.97 \%(1.26 \%)$ and $1.23 \%$ $(1.26 \%)$, respectively; $\mathrm{p}=0.6)$.

In a series of 24 of the patients, two needle liver biopsies were performed during laparoscopy, one from the right and one from the left lobe of the liver. The AgNOR-PI values ranged from $0 \%$ to $4.5 \%$ in the liver biopsies obtained from the right lobe, and from $0 \%$ to $4.6 \%$ in the liver biopsies obtained from the left lobe. When the AgNOR-PI of the biopsies obtained from the right and the left lobes were related to each other, a highly significant correlation was found $(r=0.93 ; \mathrm{p}<0.001)$.

During the mean (SD) follow up time of 65.5 (36.29) months (range, 12-143; median, 
Table 1 Impact of patient characteristics on HCC development evaluated by univariate analysis

\begin{tabular}{|c|c|c|c|c|c|c|}
\hline Variable & $\begin{array}{l}\text { Number (\%) } \\
\text { of patients }\end{array}$ & $\begin{array}{l}\text { Probability of } \\
\text { HCC development }\end{array}$ & $p$ (Matel Cox) & $p$ (Breslow) & Odds ratio & $95 \% C I$ \\
\hline \multicolumn{7}{|l|}{$A g N O R-P I$} \\
\hline$<2.5$ & $134(76.1)$ & $17.2 \%$ & 0.0001 & 0.0001 & 6.91 & 3.25 to 14.69 \\
\hline$\geqslant 2.5$ & $42(23.9)$ & $59.5 \%$ & & & & \\
\hline \multicolumn{7}{|l|}{ Dysplasia } \\
\hline No LCD & $134(76.1)$ & $22.4 \%$ & 0.0008 & 0.0001 & 2.59 & 1.25 to 5.35 \\
\hline LCD & $42(23.9)$ & $42.9 \%$ & & & & \\
\hline \multicolumn{7}{|l|}{ HBV infection } \\
\hline HBsAg negative & $145(82.4)$ & $24.0 \%$ & 0.0034 & 0.0015 & 2.42 & 1.08 to 5.42 \\
\hline HBsAg positive & $31(17.6)$ & $43.3 \%$ & & & & \\
\hline \multicolumn{7}{|l|}{ HCV infection } \\
\hline HCV negative & $42(52.5)$ & $18.4 \%$ & 0.2783 & 0.2394 & 2.14 & 0.77 to 5.91 \\
\hline HCV positive & $38(47.5)$ & $33.3 \%$ & & & & \\
\hline
\end{tabular}

AgNOR-PI, silver staining nucleolar organising region proliferation index; CI, confidence interval; HbsAg, hepatitis B surface antigen; HBV, hepatitis B virus; HCC, hepatocellular carcinoma; HCV, hepatitis C virus; LCD, liver cell dysplasia.

67), hepatocellular carcinoma was diagnosed in 48 of 176 patients $(27.3 \%)$. Patients who developed hepatocellular carcinoma had a mean AgNOR-PI significantly greater than patients who did not show any evidence of neoplastic transformation $(2.15 \% \quad(1.65 \%)$ versus $1.02 \%(1.07 \%)$; $<0.001)$. For statistical analysis, the series of 176 patients was divided into two groups according to their AgNOR-PI values, using a cut off value of $2.5 \%$, which was obtained by using the receiver operating characteristic curve and the Youden index. The hepatocellular carcinoma free survival curves for the two groups of patients are shown in fig 2 . The cumulative probability of hepatocellular carcinoma development was significantly greater in the group of patients with an AgNOR-PI $\geqslant 2.5 \%$ (25 of 42) than in patients with an AgNOR-PI < 2.5\% (23 of 134) $(\mathrm{p}<0.0001)$. Univariate analysis demonstrated that the cumulative probability of hepatocellular carcinoma development was also significantly higher in patients with liver cell dysplasia and HBV infection, while $\mathrm{HCV}$ infection did not indicate a higher risk for hepatocellular carcinoma (table 1). Multivariate analysis including AgNOR-PI, liver cell dysplasia, HBsAg positivity, and HCV infection (the latter parameter available only in a series of 80 patients) as covariates demonstrated that the AgNOR-PI parameter was the only significant predictor of hepatocellular carcinoma development.

For the total time interval, the hepatocellular carcinoma incidence rate was 0.105 subjects/ year in the group of patients with an AgNOR-PI $\geqslant 2.5 \%$ and only 0.028 subjects/ year in the group of patients with an AgNOR-PI $<2.5 \%$. The time interval between the diagnosis of cirrhosis and the development of hepatocellular carcinoma was significantly shorter in patients with an AgNOR-PI $\geqslant 2.5 \%$ $(\mathrm{n}=25)$ than in patients with an AgNOR-PI $<2.5 \% \quad(\mathrm{n}=23)$ : $35.08 \quad(18.68)$ months; range, 9-72 versus 56 (27.21) months; range, $16-111(\mathrm{p}<0.001)$. The hepatocellular carcinoma incidence rate evaluated over the first three years of follow up was 0.134 subjects/year in the group of patients with an AgNOR-PI $\geqslant 2.5 \%$ and 0.014 subjects/year in the group of patients with an AgNOR-PI $<2.5 \%$ (ratio $=9.6)$. Over the successive three years, the hepatocellular carcinoma incidence rate of the group of patients with a high AgNOR-PI
(0.157 subjects/year) remained quite constant, whereas that of patients with a low AgNOR-PI (0.039 subjects/year) increased significantly $(\mathrm{p}<0.05)$, with a ratio of 4.0 .

\section{Discussion}

These results show that a high hepatocyte proliferation rate was the major risk factor for hepatocellular carcinoma development in a group of 176 cirrhotic patients independent of the aetiology of the liver disease. Multivariate analysis of predictive parameters of hepatocellular carcinoma onset in cirrhotic patients (HBsAg positivity, HCV infection, liver cell dysplasia, and AgNOR-PI) showed that AgNOR-PI was the most powerful variable. Among the patients who developed hepatocellular carcinoma, the time interval between recruitment and diagnosis of the cancer was significantly shorter in those with a high AgNOR-PI than in those with a low AgNORPI.

The AgNOR-PI was evaluated by measuring the percentages of hepatocytes with an AgNOR protein quantity $>7 \mu \mathrm{m}^{2}$, indicative of hepatocyte proliferation state. ${ }^{6}$ AgNOR protein measurement was chosen as the method for cell kinetics evaluation in the present study for the following reasons. The AgNOR protein can be measured in routinely processed tissue samples, independent of processing procedures, in contrast to the other methods currently used for cell kinetics evaluation. Indeed, in vivo bromodeoxyuridine (BrdU) administration followed by the immunohistochemical identification of S phase cells with anti-BrdU antibodies is the most accurate method presently available for defining cell proliferation. However, the technique requires BrdU infusion, which seriously limits its application in routine pathology. The only other method available for cell kinetics evaluation of routinely processed tissue samples is Ki-67/MIB-1 immunostaining. This method is dependent on length of fixation ${ }^{19}$ and, therefore, is not suitable for studies using tissue sections processed in a nonhomogeneous manner. Moreover, a significant spread of labelling indices with Ki-67/MIB-1 immunostaining has been revealed in duplicate samples. ${ }^{20}$

Measurements of hepatocyte proliferative activity were carried out on a single hepatic biopsy for each patient. We found that a single sample was representative of the kinetic state of 
the whole liver. Furthermore, in 24 patients in whom two needle liver biopsies from different lobes were available, a strict correlation was found $(r=0.93)$ between the two series of AgNOR-PI scores. This demonstrates that: (1) proliferative hepatocyte activity is uniformly distributed throughout the liver, and (2) a single liver biopsy is sufficient to obtain information about the hepatocyte proliferative activity of whole liver.

The present results are consistent with previous reports that have stressed the importance of hepatocyte proliferative activity for hepatocellular carcinoma development in cirrhotic patients. ${ }^{41-24}$ However, in those studies, the numbers of patients were very small, the follow up period was short, and hepatocyte proliferative activity was the only variable evaluated. Indeed, multivariate analysis taking into consideration other well established parameters for predicting hepatocellular carcinoma development, such as HBsAg positivity, $\mathrm{HCV}$ infection, and the presence of liver cell dysplasia, was not performed.

A relation between high proliferative activity and hepatocellular carcinoma development in cirrhotic patients is not surprising in the light of the experimental model of hepatocarcinogenesis. Hepatocyte proliferative activity increases progressively in the intermediate noncancerous lesions that precede the onset of hepatocellular carcinoma. ${ }^{25} 26$

In this study, univariate analysis showed that HBsAg positivity and liver cell dysplasia were significantly related to the development of hepatocellular carcinoma in cirrhotic patients, in agreement with previous data. ${ }^{2}{ }^{3}$ The importance of these risk factors appeared to be strictly related to the high hepatocyte proliferative activity of the two groups of patients selected by the two parameters. Indeed, the $\mathrm{HBsAg}$ positive patients had AgNOR-PI values significantly higher than those of all other patients, and it is worth noting that sustained hepatocellular proliferation precedes the onset of hepatocellular carcinoma in hepatitis surface antigen transgenic mice. ${ }^{27}$ Regarding liver cell dysplasia, our data have shown that a strict relation exists between a high AgNOR-PI and the presence of dysplasia. This observation is consistent with previous findings, ${ }^{28}$ showing that AgNOR protein quantity was greater in dysplastic cirrhosis than in cirrhosis alone. Liver cell dysplasia was evaluated by applying the criteria proposed by Anthony et al, referring to the so called "large" liver cell dysplasia. Because proliferating cells have larger nuclei than resting ones, the diagnosis of liver cell dysplasia is conditioned by the presence of a sustained hepatocellular proliferation. Thus, liver cell dysplasia and a high AgNOR-PI may be considered to be morphological expressions of the same biological phenomenon. Most likely, liver cell dysplasia was a less powerful predictor of the onset of hepatocellular carcinoma than the AgNOR-PI because of the different procedures used for the evaluation of the two parameters. AgNOR-PI was defined objectively by computer assisted morphometric analysis, while the diagnosis of liver cell dysplasia is less accurate, being dependent on observer subjectivity and based on the presence of clusters of dysplastic hepatocytes.

The present observation that hepatocyte proliferative activity is the most important risk factor for hepatocellular carcinoma development indicates that this parameter should be evaluated routinely in those cirrhotic patients for whom liver biopsy is not otherwise inadvisable. The identification of two groups of cirrhotic patients at high and low risk, respectively, has important clinical implications. It will be possible to identify high risk patients and perform more frequent ultrasound scanning for early diagnosis of hepatocellular carcinoma, thereby improving patient survival by allowing medical and surgical treatment of very early neoplastic lesions. Secondly, high risk patients could be selected for pharmacological treatment that might prevent the onset of hepatocellular carcinoma. In this respect, it has recently been reported that $\alpha$ interferon reduces the risk of hepatocellular carcinoma development in cirrhotic patients. ${ }^{29}$ Finally, the observation that the incidence rate of hepatocellular carcinoma in patients with low proliferative activity was greatly increased during the second three year follow up period suggests that proliferative activity is more likely to increase along with the progression of the underlying cirrhosis. Therefore, it would be advisable to repeat hepatocyte kinetic evaluation three years after the histological diagnosis of cirrhosis to update the patient's neoplastic risk.

This work was supported by Grants from the Ministero della Ricerca Scientifica e Tecnologica (MURST), Pallotti's Legacy for Cancer Research, Regione Emilia Romagna (DGR 4243/ 1991), the Italian Association for Cancer Research (AIRC, Milan), and University of Bologna (funds for selected research topics)

1 Colombo M, De Franchis R, Del Ninno E, et al. Hepatocellular carcinoma in Italian patients with cirrhosis. $\mathrm{N} \mathrm{Engl} \mathcal{F}$ Med 1991;325:675-80.

2 Borzio M, Savino B, Roncalli M, et al. Liver cell dysplasia is a major risk factor for hepatocellular carcinoma in cirrhosis: a prospective study. Gastroenterology 1995;108: 812-17.

3 Ganne-Carrie N, Chastang C, Chapel F, et al. Predictive score for the development of hepatocellular carcinoma and additional value of liver large cell dysplasia in western patients with cirrhosis. Hepatology 1996;23:1112-18.

4 Derenzini $M$, Trerè $\mathrm{D}$, Oliveri $\mathrm{F}$, et al. Is high AgNOR quantity in hepatocytes associated with increased risk of hepatocellular carcinoma in chronic liver disease? $f$ Clin Pathol 1993;46:727-9.

5 Derenzini $\mathrm{M}$, Ploton D. Interphase nucleolar organizer regions in cancer cells. Int Rev Exp Pathol 1991;32:149-92.

6 Pession A, Farabegoli F, Trerè D, et al. The Ag-NOR proteins and transcription and duplication of ribosomal genes in mammalian cell nuclei. Chromosoma 1991;100: 242-50.

7 Sirri V, Roussel P, Trerè D, et al. Amount variability of total AgNOR proteins, nucleolin and protein B23 in cells stimulated to proliferate. F Histochem Cytochem 1995;43:887-93.

8 Bolondi L, Gramantieri L, Chieco P, et al. Enzymatic cytoBolondi L, Gramantieri L, Chieco P, et al. Enzymatic cyto-
chemistry, ploidy and AgNOR quantitation in small undefined nodular lesions in liver cirrhosis. Dig Dis Sci 1996;41: 4:800-8.

9 Kuo G, Choo QL, Alter J, et al. An assay for circulating antibodies to a major etiologic virus of human non-A non-B hepatitis. Science 1989;244:362-4

10 Ploton D, Menager M, Jeannesson P, et al. Improvement in the staining and in the visualization of the argyrophilic proteins of the nucleolar organizer regions at the optical level. Histochem $\mathcal{F}$ 1986;18:5-14.

11 Öfner D, Bankflavi A, Riehemann K, et al. Wet autoclave pretreatment improves the visualization of silver-stained pretreatment improves the visualization of silver-stained nucleolar organizer-region-associated proteins in routinely
formalin-fixed and paraffin-embedded tissues. Mod Pathol 1994;7:946-50

12 Anthony PP, Ishak K, Nayak NC, et al. The morphology of cirrhosis. F Clin Pathol 1978;31:395-414. 
13 Gibson JB, Sobin LH. Histological typing of tumors of the liver, biliary tract and pancreas. International histological classification of tumors number 20. Geneva: World Health Organisation, 1978:12-30.

14 Anthony PP, Vogel CL, Barker LF. Liver cell dysplasia: a premalignant condition. $\mathcal{F}$ Clin Pathol 1973;26:217-23.

15 Mourad WA, Erkman-Balis B, Livingston S, et al. Argyrophilic nucleolar organizer regions in breast carcinoma: correlation with DNA flow cytometry, histo-pathology and lymph node status. Cancer 1992;69:1739-44.

16 Mourad WA, Connelly JF, Sembera DL, et al. Correlation of two argyrophilic nucleolar organizer region counting methods with bromodeoxyuridine labeling index: a study of metastatic tumors of the brain. Hum Pathol 1993;24:20610.

17 Kaplan EL, Meier P. Nonparametric estimation from incomplete observations. F Am Stat Assoc 1958;53:457-81.

18 Cox DR. Regression models and life-tables. 7 R Stat Soc $B$ 1972;34:87-220.

19 Manakata S, Hendricks JB. Effect of fixation time and microwave oven heating time on retrieval of the Ki67 antigen from paraffin embedded tissue. $\mathcal{F}$ Histochem Cytochem 1993;41:1241-6.

20 Torp SH. Proliferative activity in human ganglioblastomas: evaluation of different Ki67 equivalent antibodies. 7 Clin Pathol Mol Pathol 1997;50:198-200.

21 Tarao K, Shimizu A, Ohkawa S, et al. Development of hepatocellular carcinoma associated with increases in DNA synthesis in the surrounding cirrhosis. Gastroenterology 1992;103:595-600.
22 Tarao K, Ohkawa S, Shimizu A, et al. The male preponderance of hepatocellular carcinoma associated cirrhotic patients may depend on the higher DNA synthetic activity of cirrhotic tissue in men. Cancer 1993;72:369-74.

23 Ballardini G, Groff P, Zoli M, et al. Increased risk of hepatocellular carcinoma development in patients with cirrhosis with high hepatocellular proliferation. $f$ Hepatol 1994;20: 218-22.

24 Tarao K, Ohkawa S, Shimizu A, et al. Significance of hepatocellular proliferation in the development of hepatocellular carcinoma from anti-hepatitis $C$ virus-positive cirrhotic patients. Cancer 1994;73:1149-54.

25 Farber E. Response of the liver to carcinogenesis. In: Farber E, Fisher M, eds. Injury of the liver. Part A. New York: Marcel Dekker, 1979:445-6.

26 Trerè D, Derenzini $M$, Sirri V, et al. Qualitative and quantitative analysis of AgNOR proteins in chemically-induced rat liver carcinogensis. Hepatology 1996;24:1269-73.

27 Huang SN, Chisari FV. Strong, sustained hepatocellular proliferation precedes hepatocarcinogenesis in hepatitis B surface antigen transgenic mice. Hepatology 1995;21:6206.

28 Crocker J, McGovern J. Nucleolar organizer regions in normal, cirrhotic and carcinomatous livers. F Clin Pathol 1998: 41:1044-8.

29 Mazzella G, Accogli E, Sottili S, et al. Alpha interferon treatment may prevent hepatocellular carcinoma in HCVrelated liver cirrhosis. F Hepatol 1996;24:141-7. 